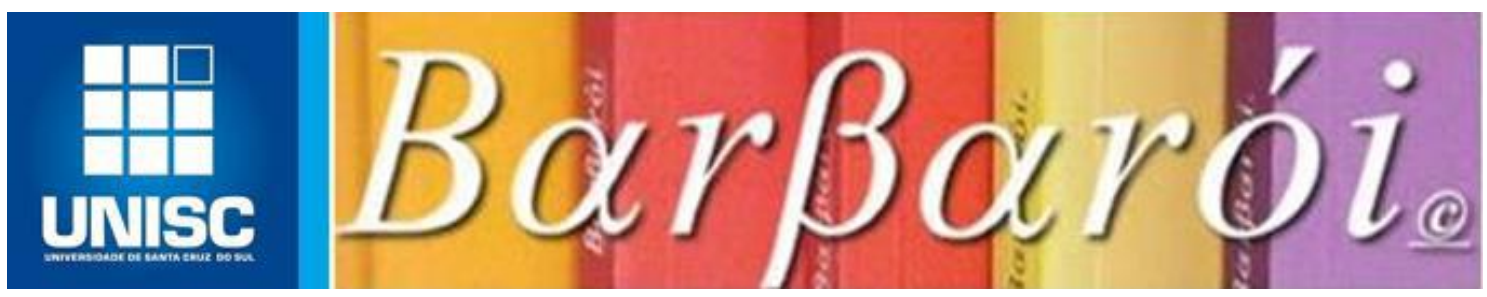

\title{
DO IMPENSÁVEL AO INSTITUÍDO: A AÇÃO COLETIVA DOS CATADORES DE MATERIAIS RECICLÁVEIS NA CIDADE DE SANTA CRUZ DO SUL
}

\author{
DOI: http://dx.doi.org/10.17058/barbaroi.v0i0.14596

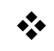

Cristiano Benites Oliveira

Universidade de Santa Cruz do Sul - UNISC-Brasil

César Hamilton Brito Góes

Universidade de Santa Cruz do Sul - UNISC-Brasil

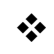

\begin{abstract}
Resumo
A inclusão dos catadores na agenda de políticas de gestão de resíduos na cidade de Santa Cruz do Sul, que culminou com a celebração de contratos de prestação de serviços públicos, foi o resultado da ação coletiva realizada pelos catadores articulados no Movimento Nacional dos Catadores de Materiais Recicláveis (MNCR), com o apoio de demais organizações da sociedade e do Estado em nível local. Houve a ocorrência de um processo em que os catadores articulados junto ao MNCR passaram de excluídos a prestadores de serviço de destinação final e coleta seletiva de resíduos neste município. Neste artigo, realizamos a interpretação sociológica desse processo e de seus limites por meio de categorias como estigma, frames de ação coletiva e repertório de conflito presentes na literatura específica sobre relações excludentes e sobre movimentos sociais. Como forma de conferir rigor hermenêutico, será utilizado material empírico do MNCR, e também, referências de estudo da dissertação e da tese de um dos autores. (OLIVEIRA, 2010; 2016) Para descrever os limites da institucionalização no contexto local serão empregados estudos sobre esse conceito e sobre a estagnação da coleta seletiva feita pela Cooperativa dos Catadores de Santa Cruz do Sul (COOMCAT). Ao final, com base na descrição desse processo contencioso, elaboraremos algumas considerações sobre o conflito que se estabelece em torno da gestão de resíduos nesta localidade.
\end{abstract}

Palavras-chave: Catadores de materiais recicláveis; frames de ação coletiva; gestão de resíduos sólidos

\section{Introdução}

O prestação de serviços públicos de coleta seletiva e destinação de resíduos sólidos concedidos a catadores de materiais recicláveis era algo impensável para muitas prefeituras. Isso porque, tradicionalmente as concessões dos serviços de limpeza urbana são feitas a empresas especializadas na destinação final de resíduos sólidos. Em Santa Cruz do Sul, o 
governo municipal não concebia os catadores enquanto prestadores de serviço, pois muitos possuem baixa escolaridade e trabalham de forma precária, vivendo em situação de pobreza e exclusão social. Sob tais condições, como esses trabalhadores poderiam ser reconhecidos como prestadores de serviços na gestão municipal de resíduos sólidos?

A destinação de materiais descartados como "lixo" por pessoas em situação de pobreza no Brasil se ampliou na década de 1980 na medida em que a reciclagem de materiais entrou na pauta da indústria, o que aumentou os tipos de materiais com potencial reciclável. Com o apoio de entidades civis, diversos grupos começaram a se organizar em forma de associações e cooperativas. Ainda que alguns grupos, ao se organizar, participem da gestão de resíduos sólidos, classificando e enfardando os materiais em unidades de triagem, eles não são reconhecidos como prestadores de serviços em muitos municípios.

Como será visto neste artigo, diversas municipalidades consideram as cooperativas dos catadores enquanto empreendimentos autônomos, que retiram sua subsistência da comercialização de materiais classificados e enfardados no mercado de recicláveis. Assim, muitas prefeituras dão suporte a essas atividades, sem, contudo reconhecer esses sujeitos enquanto prestadores de serviço público através da celebração de contrato com os catadores.

A concessão desse serviço é tradicionalmente atribuída às empresas proprietárias de capitais acumulados, tais como recursos de saber, financeiros, tecnológicos. Pelo fato da grande maioria de catadores não possuir condições financeiras, nem meios de produção e conhecimentos sobre a indústria dos recicláveis, eles encontram-se submetidos economicamente a intermediários comerciais de materiais recicláveis (atravessadores e aparistas), e excluídos política e tecnicamente da gestão de resíduos sólidos nos municípios. Além disso, eles são assolados por estigmas vinculados ao lixo e à precariedade das suas condições de vida e de trabalho.

Assim, são reproduzidas relações sociais que reforçam o paradoxo de uma indústria lucrativa em produtos e serviços, mas que mantém a precariedade e a exclusão social dos catadores no âmbito dessa cadeia produtiva. Em suma, a questão que trazemos para ser elucidada neste artigo consiste em como o poder público local do município de Santa Cruz do Sul pôde reconhecer os catadores como contratados para prestação de serviços de coleta e reciclagem? Quais são os limites desse reconhecimento?

O caso da cidade de Santa Cruz do Sul, com a contratação dos catadores organizados em cooperativa para a coleta e destinação de resíduos, é fundamental para se entender os processos coletivos instituintes e a importância da práxis desses atores. Para contextualizar suas ações coletivas, parte-se da situação social, econômica e política dos catadores.

Barbarói, Santa Cruz do Sul, Edição Especial n.54, p.<112-132>, jul./dez. 2019 
Para conferir rigor à interpretação sociológica desse processo, teoricamente serão utilizados, além das categorias acima, os conceitos de estigma (GOFFMAN,1988), reconhecimento (HONNETH, 2003) e repertório de conflito (TARROW 2009). E, empiricamente, serão empregados documentos do MNCR e relatos de suas lideranças coletados por uma tese de doutorado (OLIVEIRA, 2016) e uma dissertação de mestrado (OLIVEIRA, 2010). Também serão utilizados estudos que abordam a atuação dos catadores no município em questão.

\section{Estigma e exclusão na reciclagem de resíduos}

Existem diversos estudos acadêmicos sobre as desigualdades que assolam os catadores. Para fins interpretativos elencamos três formas principais de desigualdade: a discriminação cultural, a exploração econômica e a exclusão social. Para a interpretação dessas formas complexas de assimetria societária selecionamos textos que conceituam e explicam como ocorrem esses fenômenos na realidade da reciclagem popular.

Para começar a interpretação sobre o fenômeno discriminatório é preciso entender o estigma social atribuído aos catadores. O conceito de estigma foi traduzido para a sociologia por Erving Goffman (1988). Segundo ele, o estigma não é constituído pelos próprios sujeitos, ou seja, "o normal e o estigmatizado não são pessoas e sim perspectivas que são geradas em situações sociais durante os contatos mistos." Nesses entrecruzamentos, normais e estigmatizados são rompidas as regras culturais que definem essas identidades pessoais, colocando os estigmatizados em oposição aos normais por causa da sua situação social (Ibid., p. 149). No caso dos catadores a situação que gera a perspectiva do estigma é produzida em função dos catadores representarem o tipo de papel que os estigmatiza em relação às demais pessoas que não se encontram na situação em que vivenciam de um trabalho, socialmente desvalorizado, realizado com "lixo", cuja representação é tida por algo descartado e igualmente sem valor.

O "lixo" possui significados diversos: para as pessoas que trabalham e convivem com os resíduos é comum que desenvolvam um valor positivo acerca desse material, o qual é discrepante com o valor atribuído ao que tradicionalmente se entende por "lixo", ou seja, sujeira potencialmente ofensiva ao asseio e à organização e que, por isso, deve ser eliminada como forma de reordenamento do espaço ambiental. (SONSNISKI, 2006, p. 41-42) Esse tipo de representação também é confirmada pelas autoridades públicas ao considerá-lo como um problema de saúde pública (material contaminado e contaminante proliferador de vetores que 
transmitem doenças), ocasionando um passivo ambiental que precisa ser solucionado pelo poder público. (CABALLERO, 2008, p. 10).

Além disso, pesa sobre eles a significação relacionada a um trabalho que pode ser feito por qualquer um, até mesmo por um delinquente. Assim os catadores, mesmo não sendo delinquentes, pois exercem uma atividade honesta. Vivem uma situação ambígua, pois não se consegue diferenciar um delinquente de uma pessoa honesta quando ambas podem mexer no lixo. (MACIEL; GRILLO, 2009, p. 269; 270).

A ocupação de catador de material de reciclável é estigmatizada, mesmo quando quem o estigmatiza não tenha intenção disto. Porque, para que o catador possa obter seu sustento ele precisa "revirar o lixo ou estar em lixões". Assim esse sujeito acaba se confundindo com o objeto de seu próprio trabalho. (SEVERO; MAIA; GUIMARÃES, 2017, p. 2017) Esse estigma é confirmado ao se realizar um trabalho que associa sua identidade ao lixo é identificado pelos catadores, no momento em que são chamados de "lixeiros", (OLIVEIRA, 2010, p. 102) estigma que compartilham com garis, varredores e demais trabalhadores da limpeza pública.

A desqualificação da identidade dos catadores e a ambiguidade dessa ocupação também é reforçada pelos meios de comunicação, ao ser agregados problemas relacionados à falta de lugar para deixar as crianças, às perturbações no ambiente urbano, e aos maus-tratos com animais de tração. Isso aparece da seguinte forma por uma liderança dos catadores em Santa Cruz do Sul: “A tensão sempre fez parte do cotidiano dos(as) catadores(as) no município. Os meios de comunicação insistiam em transmitir uma imagem de desorganização, de incômodo com a presença de catadores(as) nas ruas do centro e a problemática das crianças e dos cavalos.” (JANDREY, 2013, p. 5).

Em termos econômicos, estima-se que os catadores contribuam com a destinação de 90\% de todo o material descartado que alimenta a indústria nacional de reciclagem (IPEA, 2011). Contudo, os catadores permanecem trabalhadores pouco reconhecidos desta indústria, cuja sustentação é viabilizada através da lida cotidiana desses sujeitos. A grande maioria dos catadores encontra-se, de modo tardio, com pouco acesso aos direitos e às garantias relativas ao seu trabalho, a não ser a renda obtida através da venda dos materiais coletados aos intermediários comerciais do mercado de recicláveis. Esses intermediários controlam importantes etapas do ciclo das cadeias produtivas dos materiais recicláveis pós-consumo.

Tais intermediários estabelecem os preços dos materiais a serem pagos aos catadores. Sendo assim, os preços de mercado não são determinados por aqueles que vendem a mercadoria, mas, ao contrário, pelos que a compram. Isso evidencia determinados traços Barbarói, Santa Cruz do Sul, Edição Especial n.54, p.<112-132>, jul./dez. 2019 
estruturais da formação dos preços pagos aos catadores sobre os materiais coletados e classificados. Estes preços são firmados por um pequeno número de compradores, ou seja, por um "oligopsônio". O oligopsônio consiste em um formato de mercado dentro do qual existem poucos compradores (chamados de "oligopsonistas") que mantêm relações comerciais com muitos vendedores. ${ }^{1}$ (GONÇALVES, 2003, p. 143).

Esses estudos acerca das formas de como são acumuladas as riquezas advindas da reciclagem ajudam a demonstrar o quanto os catadores ainda permanecem submetidos a relações de trabalho que representam o paradoxo de uma atividade econômica altamente lucrativa, mas que torna precária a atividade laboral humana. Essa forma de acumulação, que ocorre nas primeiras etapas do ciclo produtivo das cadeias que compõem a reciclagem, reproduz relações de exploração que há tempos eram tidas como superadas na história do mundo do trabalho. Isso faz com que se tornem atuais certas expressões da clássica questão social $^{2}$ no âmbito das relações de produção que envolvem os catadores.

Já a exclusão social segundo Pedro Demo (2002) é caracterizada como um bloqueio que impede que os pobres obtenham benefícios em ambientes de mercado competitivos. (Ibid., p. 44) Segundo ele, pobreza e exclusão "refletem o sucesso de grupos que procuram vantagem numa economia competitiva e num ambiente político." (Ibid.) Deste modo, a organização dos interesses dominantes tende a formar "coalizões distributivas" articuladas para ganhar vantagens à revelia daqueles que se encontram dispersos ou que não conseguem competir. (Ibid.) Isso se dá porque, "excluir maiorias, mesmo que estas se sintam angustiantemente inúteis [...], implica em movimento violento de reorganização dos privilégios sociais.” (Ibid, p. 34).

A opção de uma prestação de serviço eficiente diz respeito à contratação por parte das prefeituras de médias e grandes empresas que atuam no ramo da limpeza urbana. A gestão de resíduos se torna hegemonizada por um sentido privatista. (WIRTH, 2013) Nesse modelo de gestão, os serviços de manejo de resíduos são convertidos em mercadoria, sendo a lucratividade dos serviços o objetivo principal das empresas prestadoras. Isto acaba por

1 Mesmo que o oligopsônio e o oligopólio possam representar relações "imperfeitas" de mercado, os mesmos consistem em relações responsáveis pela concentração de riquezas no interior de diversos ciclos que movimentam cadeias produtivas tais como a da reciclagem. (GONÇALVES, 2003)

2 O termo questão social, desde o ponto de vista histórico, está relacionado com o processo desnaturalização das péssimas condições de existência das populações que se tornavam ao mesmo tempo agentes e vítimas da mercantilização de sua força de trabalho a partir da, então, nascente revolução industrial iniciada nos centros urbanos do continente europeu a partir do século XIX. (CASTEL, 2004, p. 238-239) 
condicionar as escolhas tecnológicas, as decisões que afetam o meio ambiente e as condições de trabalho a tal imperativo. (WIRTH; OLIVEIRA, 2016, p.7).

No sentido privatista de gestão, o poder público municipal realiza a contratação de empresa para a prestação integral dos serviços de manejo de resíduos ou de determinadas partes dos mesmos. De forma frequente, há inúmeras dificuldades do órgão público municipal, que possui tal incumbência, de fiscalizar a qualidade da prestação desses serviços. Isso acontece porque muitas vezes, as repartições não contam com as ferramentas técnicas tais como sistemas de informação, banco de dados, rastreamento de caminhões, etc - e tampouco com funcionários qualificados do quadro técnico - uma vez que diminuição das áreas técnicas do Estado consiste em uma tendência que avança a partir das terceirizações de serviços. (MARQUES, 2005; GANDY, 1994, p.11).

Em função disto é que as empresas passam a ter um papel muito mais abrangente do que uma simples prestação de serviços, pois elas influenciam na própria definição de como tais serviços serão prestados, bem como na decisão dos seus custos e preços. (WIRTH; OLIVEIRA, 2016, p. 7).

Assim, o sentido privatista situa os programas de coleta seletiva na marginalidade dos sistemas de gestão dos resíduos. Isso pode ser constatado já na década de 90 em que havia uma série de inciativas projetos e programas localizados de coleta seletiva em diversas cidades do país, que ocorriam à margem das políticas de limpeza urbana e de destinação de resíduos. (EIGENHEER, 1993).

Para se ter uma ideia, no Rio Grande do Sul em 175 municípios existe alguma iniciativa de coleta seletiva. Em 55 municípios, cooperativas de catadores realizam a coleta seletiva ou parte dela. Entre esses municípios apenas 20 municípios possuem contrato estabelecido entre as cooperativas de catadores e as Prefeituras. (WIRTH, 2015, p. 162).

Já sobre os catadores, em Santa Cruz do Sul, conforme os dados do censo de 2010, 664 pessoas se declararam "catadores de lixo". A idade média desses sujeitos é de 36 anos, $40,66 \%$ são mulheres, $36,3 \%$ são negros, $13,3 \%$ são analfabetos, $16,2 \%$ possuem ensino fundamental completo e 3,3\% completaram o ensino médio. (IPEA, 2013).

De forma incipiente, a criação da oportunidade política de contratação vai ganhando corpo. Ela não fazia parte da agenda de políticas públicas em Santa Cruz do Sul. A inclusão dos catadores enquanto prestadores de serviços públicos é uma pauta de reivindicação do MNCR e começou a ser discutida nessa cidade a partir da atividade sociopolítica do referido movimento. O movimento dos catadores lançou essa discussão a público, e pautou a si mesmo com esse desafio coletivo lançado às elites empresariais do lixo e às autoridades municipais. Barbarói, Santa Cruz do Sul, Edição Especial n.54, p.<112-132>, jul./dez. 2019 
O início, desdobramentos e desfechos desse processo serão vistos a seguir com o aux llio de dados empíricos interpretados através da teoria da ação coletiva por meio da mobilização política. (TARROW, 2009; 2011)

\section{Frame ecológico e organização}

Segundo Sidney Tarrow, os quadros interpretativos das ações coletivas, ou os "frames de movimento" consistem em uma forma de entendimento cognitivo, utilizada para enfatizar "a gravidade e a injustiça de uma condição social" ou redefinir como "injusto ou imoral o que era visto anteriormente como desastroso, mas talvez tolerável.” (TARROW, 2009, p. 143144).

A partir de frames, os movimentos nomeiam "os descontentamentos, conectando-os a outros descontentamentos" formando, assim quadros repletos de sentidos, os quais dialogam com "as predisposições culturais de uma população" e enviam "uma mensagem uniforme para os detentores de poder e outros." (Ibid.) A constituição de frames está relacionada com a generalização de descontentamentos, e contribui para a definição de um "nós" e de um "eles" no interior de um contexto de conflito. (Ibid. 41). Os enquadramentos interpretativos também buscam dignificar e justificar as ações coletivas, aperfeiçoando suas perspectivas políticas. (Ibid. 121).

A combinação entre a perspectiva teórica dos frames e o estudo das oportunidades políticas permite olhar as relações entre as estruturas sociais e os elementos culturais. Isso quer dizer que as estruturas que proporcionam oportunidades políticas abrem espaço à ação coletiva. Não obstante, a apropriação das oportunidades políticas depende dos temas que possuem relação com os frames, ou seja, as oportunidades precisam parecer propícias para se tornarem objetos da ação coletiva. (ROSA; MENDONÇA, 2011, p. 652).

Isso quer dizer que o processo de referenciamento interpretativo faz com que as oportunidades políticas possam ser percebidas. (MEYER, 2002, p. 15) Tal processo perceptivo diz respeito às interpretações inseridas em um frame de entendimento que proporciona campos argumentativos, os quais, por sua vez, abrem as oportunidades políticas para o debate. (BARKER; LAVALETTE, 2002, p. 142,143) É a partir dos conflitos pela apropriação das oportunidades políticas que pode se desenvolver um processo estratégico (strategizing process).

O frame ecológico foi utilizado de duas formas estratégicas: uma, para que os catadores pudessem reconhecer a si próprios; e outra, para que aproveitassem a oportunidade política de ambientalização do seu trabalho. Desse modo, o frame ecológico contribuiu para 
que o estigma dos catadores pudesse ser enfrentado tanto para dentro da categoria, quanto para fora dela. O reconhecimento que o catador confere a si próprio é a uma forma de enfrentamento ao estigma que desvaloriza sua identidade pessoal e social. Isso se deve ao fato de que existe uma relação direta entre o trabalho dos catadores e sua identidade. Nesse sentido, Honneth (2008, p. 47) afirma que os sujeitos coletivos derivam grande parte da identidade de seus membros a partir de seu papel no processo de trabalho.

A valorização profissional almejada pelos catadores pode ser verificada a partir do momento em que os mesmos passam a compreender a si mesmos enquanto trabalhadores. Esta forma de compreensão, por conseguinte, proporciona a atribuição de outro sentido além da busca pela sobrevivência.

Outro importante fator é a reafirmação de uma identidade coletiva de agente ambiental como forma de aproveitamento de uma oportunidade política concreta, pois a sua atividade de trabalho sofre um processo de ressignificação a partir de um alinhamento com as concepções do poder público. Os catadores, de problema social passam a ser concebidos como solução ambiental. A estruturação, por parte dos poderes públicos municipais, de associações e cooperativas possibilita uma articulação socioambiental para se equacionar e encaminhar a problemática de destino final dos resíduos para a reciclagem. (OLIVEIRA, 2016).

Deste modo, houve um alinhamento entre os catadores e o poder público em relação ao frame ecológico a partir de uma visão de gestão "ambientalizadora", que começava a pautar as medidas relativas à gerência da limpeza urbana, transformando a problemática dos resíduos em uma nova questão pública. (CABALLERO, 2008, p. 8) Isso possibilitou o aproveitamento de oportunidades políticas que consistiram no processo de organização dos catadores com o apoio do Governo Municipal para a estruturação de uma unidade de triagem (“galpão de reciclagem”) sob a administração da Associação Ecológica dos Catadores de Materiais Recicláveis de Santa Cruz do Sul (ASECMAR), constituída em 2003 com o apoio de uma organização da sociedade civil chamada Ecos da Natureza. (JANDREY, 2013, p. 4).

Os catadores organizados no MNCR aderiram à construção deste frame porque conseguem perceber as oportunidades de acesso às instituições e de alinhamentos que o mesmo carrega em si. Isto pode ser constatado em uma cartilha de formação política do MNCR, em que se lê: "Portanto, nos fundamentos de atuação do MNCR está a luta pela coleta seletiva [...] por acreditar que os catadores são os primeiros agentes ambientais a reciclar a matéria-prima que grande parte da sociedade chama de 'lixo'.” (MNCR, 2010, p. $15)$. 
Note-se que com a adesão do MNCR ao referido frame, o reconhecimento da identidade coletiva inicial dos catadores atrelara-se a uma estratégia de ambientalização do seu trabalho. Para entender este processo que vincula a identidade à estratégia possibilitada por uma conjuntura específica, utilizam-se elementos da perspectiva de Honneth (2003, p. 200) que concebe a compreensão cultural de uma sociedade sobre si mesma, como um fator para o estabelecimento dos critérios de avaliação sobre as capacidades e as realizações dos sujeitos em suas ações para implementar valores culturalmente reconhecidos, os quais acabam por constituir objetivos coletivamente compartilhados entre os sujeitos.

Neste sentido, para traçarem sua estratégia de ação, os catadores consideram que o crescimento da importância atribuída ao encaminhamento adequado da questão ambiental figura como um grande objetivo comum das sociedades contemporâneas. Não somente nas instituições, mas, no interior da própria cultura social, o alto grau de valoração que ganhou essa temática contribui para que seja criado, todo um campo de relações propício para que se constituam critérios de avaliação positiva acerca das realizações e das potencialidades dos catadores e de seu papel para a consecução de um objetivo socialmente compartilhado.

O frame ecológico consiste na seleção de símbolos possíveis de um reservatório cultural feito pelos organizadores com a intenção de fazer uma "mediação entre o entendimento cultural do grupo ao qual se dirigem, suas próprias crenças e aspirações e suas situações de luta.” (TARROW, 2009, p. 143).

Com base nesses elementos evidenciados por esse enquadramento interpretativo, os catadores da ASECMAR dão início, no dia 20 de fevereiro de 2006, a um projeto piloto de coleta seletiva feito de forma autônoma (sem suporte do governo municipal) como forma de pautar a opinião pública a seu favor. Tal como demonstra o excerto abaixo:

[...] iniciou-se a Coleta Seletiva Solidária no bairro Avenida. Catadores(as) uniformizados(as) passavam nas casas explicando aos moradores o projeto e marcando o dia e hora em que a coleta seria realizada. Foram entregues panfletos. A iniciativa obteve apoio da mídia local, que veiculou matérias e o spot da coleta nas rádios. No segundo mês, o projeto foi ampliado para o bairro Várzea e posteriormente ao bairro Cohab. (ASECMAR, 2006)

A citação acima ilustra a implementação de um repertório de conflito oposto a ações violentas, cuja denominação (ainda sem tradução para o português) é contained behavior. (TARROW, 2011, p. 99) Ele consiste em um conjunto de ações planejadas para a construção de ações rotineiras aceitas ou facilitadas pelas elites e entendidas pela população. É o repertório de conflito mais utilizado entre os movimentos sociais, pois tende à institucionalização das suas atividades. Contudo, sua principal fraqueza é a repetitividade, que ocasiona um baixo nível de empolgação nos atores coletivos.

Barbarói, Santa Cruz do Sul, Edição Especial n.54, p.<112-132>, jul./dez. 2019 
Esse tipo de repertório, consolidado em forma de coleta seletiva solidária autônoma busca conferir prestígio aos catadores como forma de reconhecimento que estes demandam para a sua autorrealização. Nesse sentido, se torna possível constatar que uma tensão impregna as formas modernas de organização da estima social submetendo-as a um conflito de ordem cultural. (HONNETH, 2003, p. 206) Trata-se de um conflito simbólico entre o estigma e o reconhecimento, para o qual os distintos grupos sociais buscam interpretações díspares como meios de elevar sua força em referência às finalidades gerais de uma sociedade. (Ibid., p. 207) Dentro deste tipo de conflitualidade, é que os catadores procuram a consolidação de uma estratégia de fortalecimento da sua atividade produtiva e da sua identidade, enquanto uma forma de elevar a estima social desses sujeitos por meio do processo de ambientalização de seu trabalho.

Os resultados da implementação desse repertório foram profícuos. Pautados pela estratégia de ambientalização, os catadores da ASECMAR conquistam um galpão no bairro Avenida, com o aluguel custeado pela Prefeitura, e envio de cargas de materiais recicláveis coletados pelos caminhões da empresa prestadora deste serviço. Projetos sociais garantem uma capitalização inicial para o grupo com carrinhos e prensas e elevador de fardos de material reciclável. (JANDREY, 2013, p. 5).

Com os objetivos estratégicos de ambientalização do trabalho dos catadores e o consequente reconhecimento da identidade pessoal e social dos catadores vinculada à sua atividade laboral foi possível o aproveitamento das oportunidades políticas na forma de organização e instituição da associação de catadores, aluguel de galpão e estruturação produtiva inicial dos empreendimentos. Esse foi o início da consolidação do grupo de catadores que viriam a conformar uma base do MNCR.

Ao final da ocorrência deste frame, já na transição para o frame setorial, eram demonstrados seus limites. A repetitividade das ações do repertório de conflito, a remuneração dos catadores mantida no mesmo patamar dos desorganizados e os custos de produção subtraídos da venda do resíduo reciclável coletado, triado e comercializado começaram a se tornar evidentes para os catadores da ASECMAR.

A precariedade dos catadores individuais e familiares era substituída pela precariedade do trabalho no galpão de reciclagem gerido pela associação. Isso porque o que é recebido em função da quantidade de materiais comercializada não é suficiente para cobrir os custos de produção, os quais tendem a aumentar constantemente a despeito da variação dos preços percebidos pela venda dos materiais. (OLIVEIRA, 2016, p. 85). 
Assim, a ASECMAR abre mão do projeto de coleta seletiva autônoma, pois, para muitos catadores era preferível trabalhar da forma anterior que permanecer organizados e receber a mesma remuneração que catadores, cujo trabalho é feito em itinerários de coleta aleatórios e individuais. Isso é ilustrado da seguinte forma:

[...] o projeto piloto da coleta seletiva solidária autônoma perdia sua força, pois não
havendo remuneração pelo serviço, era mais vantajoso para os catadores manterem
seus roteiros antigos. Sendo assim, decidiu-se que o projeto só iria ter
prosseguimento quando de fato a Prefeitura contratasse os(as) catadores(as) para
prestar este serviço. (JANDREY, 2013, p. 5)

Parecia que durante o frame ecológico, os catadores poderiam sustentar-se econômica e financeiramente com a simples manutenção do acesso aos materiais recicláveis levados aos empreendimentos de catadores, ou coletados de forma autônoma. Não estava consolidada para a Prefeitura a possibilidade de contratação e de pagamento por serviços prestados pelos catadores.

Essa possibilidade foi ganhando corpo a partir da vigência de outro enquadramento interpretativo: o frame setorial. Nesta outra forma de perceber as oportunidades políticas conquistadas em nível nacional, os catadores começam a inovar seus repertórios de conflito e a lançar desafios mais claros à empresa prestadora dos serviços de destinação e coleta de resíduos por meio do questionamento ao poder público municipal.

\section{Frame setorial e ação disruptiva}

O ponto de partida do frame setorial foi a criação do MNCR a partir do aproveitamento de uma oportunidade política sobre os apoiadores externos, os quais mantinham relações de tutela com os catadores. Isso fica claro a partir do recorte textual:

\footnotetext{
Durante o debate, iniciamos considerando que no início o MNCR foi concebido por agentes externos do terceiro setor que almejavam uma entidade nacional com base em diversos Estados para poder representar os catadores frente a vários organismos de captação de recursos para os seus projetos e a sustentação dos seus cargos burocráticos. [...] se o MNCR não tivesse sido criado naquele Primeiro Congresso dos Catadores e População de Rua em julho de 2001 em Brasília, essas entidades de qualquer forma fundariam uma entidade nacional qualquer para levar adiante os seus planos. O fato de ter saído um movimento social foi um grande avanço. (MNCR, 2007b)
}

O MNCR nasce enquanto uma expressão de autonomia. Em síntese, esse movimento é um ator coletivo que procura manter a categoria dos catadores articulada em nível nacional desde o ano de 2001, ano de sua fundação Desde lá, a ocupação profissional de catador de 
material reciclável foi reconhecida formalmente em 2002 sob o número 5192-05 da Classificação Brasileira de Ocupações (CBO). ${ }^{3}$

Um dos marcos desse enquadramento interpretativo foi a reivindicação pelo serviço a ser prestado na coleta seletiva. Esse ponto de pauta foi apresentado pelo movimento em 2001 em sua primeira declaração pública: a Carta de Brasília. (MNCR, 2001) Essa pauta passa a ser reiterada em diversos encontros que configuravam o processo de ampliação do frame Brasil afora.

O MNCR estabelece interlocução com o governo federal e consegue pautar a agenda da política de gestão de resíduos, primeiramente, com Lei $\mathrm{N}^{\circ}$. 11.445/2007 que estabelece a Política Nacional do Saneamento Básico. Esse diploma jurídico altera o Inciso XXVII do Artigo $\mathrm{N}^{\circ}$. 24 da Lei $\mathrm{N}^{\circ}$. 8.666/1993 (Lei das Licitações), colocando em seu lugar a seguinte redação:

É dispensável a licitação: [...] XXVII - na contratação da coleta, processamento e comercialização de resíduos sólidos urbanos recicláveis ou reutilizáveis, em áreas com sistema de coleta seletiva de lixo, efetuados por associações ou cooperativas formadas exclusivamente por pessoas físicas de baixa renda reconhecidas pelo poder público como catadores de materiais recicláveis, com o uso de equipamentos compatíveis com as normas técnicas, ambientais e de saúde pública. (BRASIL, 2007)

Isso traduziu um anseio de realização de uma experiência de prestação de serviço público que envolvesse participação, inclusão social e distribuição de renda. Acabou por indicar um discurso público que tornou possível aos catadores apresentar propostas de forma mais coesa, respaldadas por uma construção nacional mais ampla. (WIRTH, 2016, p. 193; 194). Esse processo se refletiu em Santa Cruz do Sul, e fez com que a oportunidade política advinda da agenda pública fosse percebida pelo MNCR dessa cidade:

No cenário nacional, isso passou a ser viável a partir do ano de 2007 com a conquista da nova Lei do saneamento Básico, que passou a permitir a contratação direta, com dispensa de licitação, das organizações dos catadores(as) para realizar a coleta nos municípios. (JANDREY, 2013, p. 6)

Assim, os catadores foram construindo o frame setorial ao conectarem noções de injustiça relacionadas com a prestação privada dos serviços de destinação e coleta seletiva de resíduos, caracterizando esse tipo de enquadramento interpretativo.

$3 \mathrm{Na}$ CBO, a denominação catador de material reciclável se refere ao catador de ferro-velho, catador de papel e papelão, catador de sucata, catador de vasilhame, enfardador de sucata (cooperativa), separador de sucata (cooperativa), triador de sucata (cooperativa). E na descrição sumária desta ocupação consta que os catadores de material reciclável são os sujeitos que catam, selecionam e vendem materiais recicláveis como papel, papelão e vidro, bem como materiais ferrosos e não ferrosos e outros materiais reaproveitáveis. (BRASIL, 2002) 
Isso tornou possível a adoção de outro repertório de conflito caracterizado por ações disruptivas. A escolha de ações coletivas varia conforme o impacto que elas podem produzir. Essas ações não são repetições mecânicas de protesto, pois passam por inovações criativas das formas disponíveis e consideradas legítimas em cada contexto. As disrupções coletivas se caracterizam pela quebra da rotina social, o que surpreende espectadores, e desorienta elites, ainda que de forma temporária. Ao contrário das ações do tipo contained behavior, as disruptivas consistem em formas eficientes de empolgação dos atores para conquista de seus objetivos. (TARROW, 2011, p. 99)

Em Santa Cruz do Sul, os catadores aderidos ao MNCR já possuíam um acúmulo de experiência em ocupações de espaços públicos, tais como prédios abandonados e repartições públicas. (JANDREY, 2013, p. 4-6) Essas experiências facilitaram a adoção de um repertório disruptivo, como ocorrido em 2008 com a ocupação e interdição da usina de triagem de Santa Cruz do Sul e com a ocupação da Prefeitura.

No dia 11 de junho de 2008 o movimento realiza um acampamento em frente à Prefeitura Municipal, para reivindicar a transferência imediata para o novo local e, novamente, a garantia de que a coleta seletiva fosse de fato destinada aos catadores. Neste 11 de junho de 2008 a Prefeitura Municipal funcionou até às 10 da noite, pois durante o dia diversas rodadas de negociação foram realizadas, com propostas e contrapropostas dos dois lados. (JANDREY, 2013, p. 9; 10)

As duas ações contribuíram para tornar a situação dos catadores visível para esta comunidade local:

\begin{abstract}
Além da sua infraestrutura de luta, os(as) catadores(as) também utilizaram o espaço público para desenvolver seu trabalho durante o dia, instalando uma balança no local e triando os resíduos coletados nas ruas. [...] O prefeito queria definir a situação naquela data ainda, pois no dia seguinte haveria uma convenção do seu partido no município. Não pegaria bem para sua reputação seus correligionários serem recepcionados por um acampamento, em frente à prefeitura. A coordenação do movimento, por sua parte, definiu que só desfaria o acampamento com uma proposta clara de definição da situação. (Ibid., p. 10)
\end{abstract}

A reivindicação era a garantia de um espaço para a associação e a destinação de cargas de materiais para a triagem. Essa pauta foi prontamente atendida, o que aumentou a visibilidade do MNCR frente aos demais catadores e à comunidade local. Desde então, foi desencadeada uma série de mobilizações e negociações com o poder público, até que em 31 de agosto de 2010, o coletivo de catadores celebrou convênio com a Prefeitura para a administração da usina municipal de triagem. (SANTA CRUZ DO SUL, 2010) Para tanto, o grupo constituiu sua segunda entidade jurídica, a Cooperativa de Catadores de Santa Cruz do Sul (COOMCAT).

O repertório disruptivo mostrou-se eficaz para a conquista dos objetivos do MNCR nesta localidade, revertendo o processo de concessão privada da destinação final de final de Barbarói, Santa Cruz do Sul, Edição Especial n.54, p.<112-132>,jul./dez. 2019 
resíduos sólidos que ocorria na usina de triagem municipal, cujo controle administrativo foi concedido aos catadores articulados nesse movimento. A conquista da gestão da usina também foi possível graças a uma rede maior de entidades sociais e comunitárias. A integração de diferentes instituições representou o início de um frame mais amplo que o setorial. Foi o começo do frame integrado e da institucionalização das conquistas obtidas.

\title{
Frame integrado e institucionalização
}

A forma de referenciamento interpretativo aqui tratado como frame integrado de ação coletiva do MNCR inicia-se com a promulgação da PNRS. Essa política tomou forma de legislação (Lei $N^{\circ}$. 12.305) sancionada em 2 de agosto de 2010, após 18 anos de tramitação no Congresso. Tal demora em sua tramitação se deve às muitas emendas recebidas ao longo desses anos em função da ausência de consenso entre os setores público e privado.

Para se ter uma ideia do reconhecimento formal que a PNRS confere aos catadores, o termo "catadores" possui doze menções no texto da lei. (BRASIL, 2010) Contudo, para que esta formalidade possa ser traduzida em benefícios para toda sociedade é necessário que se tornem vigentes algumas definições desta política, tais como:

\begin{abstract}
VI - controle social: conjunto de mecanismos e procedimentos que garantam à sociedade informações e participação nos processos de formulação, implementação e avaliação das políticas públicas relacionadas aos resíduos sólidos; XI - gestão integrada de resíduos sólidos: conjunto de ações voltadas para a busca de soluções para os resíduos sólidos, de forma a considerar as dimensões política, econômica, ambiental, cultural e social, com controle social e sob a premissa do desenvolvimento sustentável; XVII - responsabilidade compartilhada pelo ciclo de vida dos produtos: conjunto de atribuições individualizadas e encadeadas dos fabricantes, importadores, distribuidores e comerciantes, dos consumidores e dos titulares dos serviços públicos de limpeza urbana e de manejo dos resíduos sólidos, para minimizar o volume de resíduos sólidos e rejeitos gerados, bem como para reduzir os impactos causados à saúde humana e à qualidade ambiental decorrentes do ciclo de vida dos produtos, nos termos desta Lei. (BRASIL, 2010, art. $3^{\circ}$ )
\end{abstract}

As definições de controle social, gestão integrada e responsabilidade compartilhada reafirmam a necessidade de uma atuação de toda a sociedade, não apenas de um setor dela, sobre os resíduos sólidos. No município aqui referido, noções sociais, integradas e compartilhadas já eram vigentes no Fórum de Ação pela Coleta Seletiva Solidária e Reciclagem de Santa Cruz do Sul (FACS). Esse espaço agregou, desde março de 2009:

[...] universidades, sindicatos, escolas, indivíduos, prefeitura, empresas, entre outros. Agora o debate dos resíduos ganharia ainda mais expressão na cidade, ampliando seus espaços e suas influências. Foi este trabalho conjunto que resultaria na conquista da Usina Municipal de Triagem e, posteriormente, na contratação dos catadores para prestarem o serviço de coleta seletiva em Santa Cruz do Sul. (JANDREY, 2013, p. 9; 10) 
Esse conjunto de forças convergiu para que os catadores pudessem ser reconhecidos enquanto atores fundamentais do processo de gestão integrada de resíduos. Desse modo, o FACS tinha como objetivo fomentar o diálogo e a troca de informações para a criação de propostas visando implantar uma política municipal de coleta seletiva e reciclagem dos resíduos sólidos com a participação dos catadores do município:

\footnotetext{
$\mathrm{O}$ avanço, além de político, também precisava demonstrar-se na área produtiva. Era preciso que o nível organizacional do grupo se elevasse para um novo patamar. Até então, o trabalho dos(as) catadores(as) se resumia a catar, triar e enfardar seu material. Agora estavam prestando um serviço ao município, tendo que gerir o espaço para o qual a totalidade dos resíduos domésticos era enviada diariamente. Nessa conjuntura, o papel dos apoios se torna mais consistente também por parte da administração municipal e pelas entidades que compunham o FACS. A Universidade de Santa Cruz do Sul

(UNISC), por exemplo, elaborou em conjunto com o MNCR um projeto de extensão. Empresas e escolas estabeleceram parcerias em programas internos de conscientização ambiental, por meio das quais catadores(as) realizam oficinas com estudantes e trabalhadores(as). (JANDREY, 2013, p. 10; 11)
}

A atuação da militância do MNCR começou a consolidar uma ampla rede de apoio desde o início das atividades da Usina, seja para assessoramento técnico ou para projetos de captação de recursos voltados para a formação dos catadores e para a qualificação do ambiente de trabalho na usina. São destacados o projeto de extensão da UNISC, que buscou o assessoramento e a capacitação dos catadores nas áreas social e de produção; os projetos Cataforte I e II executados pela Fundação Luterana com o financiamento da Fundação Banco do Brasil e FUNASA para capacitação e estruturação de logística de transporte com equipamentos e caminhões ( 3 esteiras, 5 caminhões gaiola, prensas, balança rodoviária); e o projeto "Transformando Lixo em Solidariedade", elaborado em conjunto entre a Prefeitura e o MNCR, e financiado pelo Fundo Nacional de Meio Ambiente para qualificar a coleta seletiva solidária. (SILVEIRA et al, 2014, p. 177)

A partir dessas ações houve um processo de capitalização da COOMCAT. Isso proporcionou que no dia 10 de dezembro de 2012 fosse celebrado o contrato de prestação de serviços entre a cooperativa dos catadores e a Prefeitura, instituindo a coleta seletiva solidária.

Mesmo com infraestrutura mecânica para fazer a coleta seletiva os catadores se mantiveram com os carrinhos de tração humana para prestar o serviço, que começou em três bairros com o recolhimento de resíduo reciclável em três bairros de Santa Cruz do Sul (Centro, Higienópolis e Goiás). No final de 2013, passou a atender mais seis bairros (Santo Inácio, Universitário, Avenida, Renascença, Independência e Várzea). Atualmente a coleta seletiva feita pela COOMCAT mantém o serviço nesses nove bairros. (COOMCAT, 2019) 
O processo de institucionalização se deu com paulatinos reconhecimentos da identidade dos catadores enquanto profissionais na gestão de resíduos por parte das instituições governamentais nos níveis municipal e federal. No primeiro, esses reconhecimentos se expressam no Plano Municipal de Gestão Integrada de Resíduos Sólidos de Santa Cruz do Sul, cujos objetivos consistem em:

\footnotetext{
Buscar redução significativa do volume dos resíduos orgânicos da coleta convencional nos aterros sanitários; incentivar e promover a reciclagem dos resíduos sólidos através da educação ambiental; profissionalizar o serviço de catação realizado por catadores organizados; e aumentar a rede de parceiros da reciclagem. (SANTA CRUZ DO SUL, 2013, p. 146)
}

Esses objetivos seguem linhas da práxis realizada pelo MNCR e pelas suas redes de apoio. Em setembro de 2013, a Prefeitura, disponibilizou um pavilhão, cujo aluguel custava R\$ 4.500 mensais na zona central de Santa Cruz do Sul para a triagem de materiais provenientes da coleta seletiva solidária, e em novembro deste ano o valor do contrato pela prestação desse serviço passa a ser de aproximadamente R \$ 31.000. (CHRISTMANN, KARNOPP; AREND, 2017, p. 248)

No final do ano de 2014 a coleta seletiva solidária foi contemplada com o Prêmio Cidade Pró-Catador da Secretaria Geral da Presidência da República. A COOMCAT recebeu R\$ 120.000 desta premiação para investimentos. Foram adquiridas prensas hidráulicas, carrinhos de fardo e uma camionete com caçamba. O processo de institucionalização seguiu com a venda de outros serviços por parte da cooperativa como coleta seletiva em condomínios e logística reversa para empresas. Atualmente, a COOMCAT possui em seu quadro 52 catadores divididos entre a usina de triagem e a coleta seletiva solidária.

Isso representou o fim das ações disruptivas e a ampliação de uma agenda institucional. Mesmo assumindo os serviços de destinação da usina de triagem e de coleta seletiva que eram feitos pela empresa de limpeza urbana do município, novos limites puderam ser constatados.

\section{Limites da institucionalização}

A ideia de institucionalização da ação coletiva proposta pela abordagem teórica dos movimentos sociais (GOHN, 2008, 443-445; 450; 451) consiste em converter uma determinada organização em executora de tarefas programadas, monitoradas e avaliadas por uma instituição. Sendo tal cumprimento de tarefas institucionalizadas, pré-requisito para continuidade e existência da mesma organização. 
Dessa forma, a institucionalização das ações dos movimentos funciona como uma forma regulação normativa, que obedece a regras circunscritas em espaços estabelecidos, e não como um campo de relações mútuas de reciprocidade. (Ibid, p. 445) A perspectiva da institucionalização se refere, assim, a um campo de relações interinstitucionais e interorganizacionais em que uma instituição mais poderosa subjuga um movimento social através de uma relação assimétrica de poder.

Para se ter uma ideia dessa assimetria e da continuidade da influência privada na gestão de resíduos, Christmann, Karnopp e Arend (2017) descrevem duas características do processo de institucionalização que ocorreu em Santa Cruz do Sul: uma é o novo modelo de coleta domiciliar de resíduos através da instalação de contêineres de propriedade da empreiteira de limpeza pública, e o outro é a estagnação da coleta seletiva solidária dos catadores cooperados.

Sobre o modelo coleta conteinerizada, o início da sua implantação ocorreu em outubro de 2014, na área central de Santa Cruz. A “coleta robotizada" de resíduos consiste na instalação de contêineres para o recolhimento de resíduos - a princípio apenas os orgânicos e rejeitos -, dentro dos quais os munícipes devem descarta-los.

O gerenciamento deste modelo é realizado pela Prefeitura em parceria com a empresa contratada. A estimativa da empresa é que os contêineres possam recolher em torno de 600 toneladas por mês. Diz-se a "estimativa da empresa", porque a coleta conteinerizada não passa por um controle de pesagem. O contrato é pago por aluguel dos contêineres. Contudo, o preço deste novo modelo acaba sendo elevado, pois nele são cobrados mensalmente os custos operacionais e o aluguel fixo por contêiner.

Outra desvantagem é que, em comparação com a coleta regular, cobrada por peso, os valores repassados não diminuem conforme o aumento da educação ambiental dos munícipes, e a redução dos resíduos que ela causa - em função do descarte apenas dos rejeitos e a destinação dos recicláveis para a coleta seletiva e a reutilização dos orgânicos para hortas e jardins através da compostagem. Assim, de modo oposto, a construção de práticas sustentáveis, a coleta seletiva acaba sendo ignorada, uma vez que qualquer coisa pode ser descartada dentro do contêiner. Os recicláveis também terminam dispostos dentro dos contêineres. (Ibid., p. 252-254) Isso afeta a coleta seletiva dos catadores, e contribui para a estagnação da mesma.

\section{Considerações finais}

A partir das descrições sistematizadas neste artigo, pode-se afirmar que a identidade coletiva dos catadores articulados no MNCR em Santa Cruz do Sul é condicionada pelos Barbarói, Santa Cruz do Sul, Edição Especial n.54, p.<112-132>, jul./dez. 2019 
frames e repertórios de conflito que são adotados de forma estratégica para o aproveitamento de oportunidades políticas.

O frame ecológico contribuiu para que o estigma dos catadores pudesse ser enfrentado tanto para dentro da categoria, quanto para fora dela, através do desenvolvimento da identidade de catador enquanto agente ambiental. Esse reconhecimento é uma forma de enfrentamento ao estigma que desvaloriza sua identidade pessoal e social. Já durante o frame setorial foi pautada a prestação de serviços de destinação e coleta seletiva solidária, empregando-se ações disruptivas e se reafirmando a identidade de catador de material reciclável enquanto um setor importante par a reciclagem. Mais recentemente, no frame integrado se buscou o controle social e a responsabilidade compartilhada entre diversos atores comunitários, o que proporcionou a institucionalização dos serviços de coleta seletiva solidária, e, a vigência da identidade dos catadores enquanto profissionais na gestão de resíduos.

Não obstante, os limites do processo de institucionalização advêm da assimetria gerada pela influência do sentido privatista de gestão de resíduos, que concebe esses serviços como mercadoria, cujos lucros são proporcionados por aluguéis provenientes da propriedade privada de meios tecnológicos (contêineres e "coleta robotizada"). Isso dificulta a vigência do frame integrado, que parte das definições de controle social e responsabilidade compartilhada presentes na política nacional de resíduos, uma vez que os gestores públicos locais não conseguem sequer precisar o volume e nem o tipo de resíduos que são dispostos nos contêineres. Assim, os catadores são afetados pelos déficits em educação ambiental, pois a conteinerizada dos resíduos não estimula a separação por parte dos munícipes. A coleta seletiva solidária acaba por estar estagnada em seu desenvolvimento territorial.

A superação desses limites passa por ações que consigam desafiar as autoridades, sensibilizar a comunidade local, e angariar mais apoiadores, fortalecendo as redes de atuação dos catadores. Em suma, é preciso que novos repertórios de conflito sejam construídos dentro do frame integrado, como estratégia de apropriação de oportunidades advindas da política nacional. E, assim, no protagonismo dessas ações consiga-se fortalecer a identidade coletiva dos catadores enquanto sujeitos integrados de modo profissional à gestão de resíduos.

\section{FROM THE UNTHINKABLE TO THE INSTITUTED: THE COLLECTIVE ACTION OF THE GATHERERS OF RECYCLABLE MATERIALS IN THE CITY OF SANTA CRUZ DO SUL}

\section{Abstract}

Barbarói, Santa Cruz do Sul, Edição Especial n.54, p.<112-132>, jul./dez. 2019 
The inclusion of waste pickers in the waste management policy agenda in the city of Santa Cruz do Sul, which culminated in the conclusion of public service contracts, was the result of the collective action taken by the waste pickers articulated in the National Movement of Recyclable Materials Collectors (MNCR), with the support of local society and state organizations. There was a process in which the collectors articulated with the MNCR went from being excluded to service providers of final disposal and selective waste collection in this municipality. In this paper, we perform the sociological interpretation of this process and its limits through categories such as stigma, collective action frames and conflict repertoires of specific literature on exclusionary relations and social movements. For conferring hermeneutic rigor, empirical material from the MNCR will be used, as well as references from the dissertation and thesis of one of the authors. (OLIVEIRA, 2010; 2016) To describe the limits of institutionalization in the local context, studies on this concept and on the stagnation of selective collection performed by Recyclable Waste Collectors Cooperative of Santa Cruz do Sul (COOMCAT) will be deployed. In the end, based on the description of this contentious process, we will elaborate some considerations about the conflict around the waste management in this locality.

Keywords: Recyclable materials collectors; collective action frames; solid waste management

\section{REFERÊNCIAS}

BARKER, Colin; LAVALETTE, Michael. Strategizing and sense of context: reflections on the first two weeks of the Liverpool docks lockout, September-October 1995. In: MEYER, David S.; WHITTIER, Nancy; ROBNETT, Belinda. Social movements: identity, culture and the state. New York: Oxford University Press, 2002.

BRASIL. Lei No 11.445 de 11 de janeiro de 2007. Estabelece diretrizes nacionais para o saneamento básico [2007]. Disponível em: <http://www.planalto.gov.br/ccivil_03/_ato20072010/2007/lei/l11445.htm> Acesso em: 17/08/2015.

BRASIL. Lei No 12.305 de 2 de agosto de 2010. Institui a Política Nacional de Resíduos Sólidos [2010]. Disponível em: <http://www.planalto.gov.br/ccivil_03/_ato20072010/2010/lei/112305.htm> Acesso em: 3/9/2010.

CABALLERO, Indira N. V. Notas sobre o processo de ambientalização do lixo em Porto Alegre, RS. Trabalho aprovado na $26^{\mathrm{a}}$ Reunião Brasileira de Antropologia. Porto Seguro, Bahia, junho de 2008.

CASTEL, Robert. As transformações da questão social. In BELFIORE-WANDERLEY, Mariângela; BÓGUS, Lucia; YAZBEK, Maria C. (Orgs). Desigualdade e a questão social. São Paulo: Educ, p. 235-264, 2004.

DEMO, Pedro. O charme da exclusão social. Campinas: Autores Associados, 2002 EIGENHEER, Emílio M. Coleta Seletiva de Lixo: experiências brasileiras. Rio de Janeiro: ISER, 1993.

FÓRUM DE AÇÃO PELA COLETA SELETIVA, SOLIDÁRIA E RECICLAGEM EM SANTA CRUZ DO SUL - FACS. Histórico do FACS, 2011. In: http://facsrs.blogspot.com.br/2011/09/historico-do-facs.html. Acessado em set. 2013. 
FRAGA, Lais. S.; WIRTH, Ioli G. Tecnologia Social na cadeia produtiva da reciclagem. II Workshop Tecnologia Social e Políticas Públicas na América Latina. Unicamp, CampinasSP, 2011.

GANDY, Matthew. Recycling and the politics of urban waste. London: Earthscan, 1994 GOFFMAN, Erving. Estigma: notas sobre a manipulação da identidade deteriorada. 4. ed. Rio de Janeiro: LTC, 1988.

GOHN, Maria da Glória. Abordagens teóricas no estudo dos movimentos sociais na América Latina. Caderno CRH, Salvador, v. 21, n. 54, p. 439-455, Set./Dez. 2008.

GONÇALVES, Pólita. A reciclagem integradora dos aspectos ambientais, sociais e econômicos. Série Economia Solidária, n. 5. Rio de Janeiro, DP\&A, Fase, 2003.

GRIMBERG, Elisabeth. Coleta seletiva com inclusão social: Fórum Lixo e Cidadania na cidade de São Paulo - experiências e desafios. São Paulo: Instituto Pólis, 2007.

HONNETH, Axel. Luta por reconhecimento: a gramática moral dos conflitos sociais. São Paulo: Ed. 34, 2003.

INSTITUTO DE PESQUISAS ECONOMICAS APLICADAS (IPEA). Diagnóstico sobre os catadores de resíduos sólidos. Brasília: IPEA, 2011.

JANDREY, Fagner A. Breve relato histórico da organização dos catadores e catadoras de materiais recicláveis em Santa Cruz do Sul - RS/Brasil. In: CAMARGO, Ieda de. Sociedade atual: nós e o outro. Santa Cruz do Sul: LupaGraf. p. 155-167, 2013.

MARQUES, Ana Maura Tomesani. As políticas de limpeza urbana em São Paulo. Dissertação de mestrado. Faculdade de Filosofia, Letras e Ciências Humanas da Universidade de São Paulo. São Paulo, SP. 2005.

MEYER, David S. Opportunities and identities: bridge-building in the study or social movements. In: MEYER, David S.; WHITTIER, Nancy; ROBNETT, Belinda. Social movements: identity, culture and the state. New York: Oxford University Press, 2002.

\section{MOVIMENTO NACIONAL DOS CATADORES DE MATERIAIS RECICLÁVEIS (MNCR). Cartilha de formação 1: Caminhar é resistir. 2.ed. São Paulo, 2010.}

OLIVEIRA. Cristiano Benites. A questão social da reciclagem: um estudo sobre reflexividade, desigualdade e articulação de redes sociopolíticas no Rio Grande do Sul. Dissertação de mestrado. Programa de Pós Graduação em Ciências Socais, Universidade do Vale do Rio dos Sinos, UNISINOS. São Leopoldo, RS, 2010.

OLIVEIRA, Cristiano Benites. A dimensão constituinte da questão social da Reciclagem. Tese de doutorado. Programa de Pós-Graduação em Ciências Sociais, Universidade do Vale do Rio dos Sinos, UNISINOS. São Leopoldo, RS. 2016.

ROSA, Alexandre R.; MENDONÇA, Patrícia. Movimentos sociais e análise organizacional: explorando possibilidades a partir da teoria dos frames e oportunidades políticas. O\&S, Salvador, v.18, n.59, p. 643-660, out./dez., 2011. 
SEVERO, Ana Luiza Felix; MAIA, Fernando Joaquim Ferreira; GUIMARÃES, Patrícia Borba Vilar. O estigma da atividade de catador de material reciclável no ambiente urbano: uma análise na ótica de Erving Goffman sobre o "Lixo Extraordinário". Revista de Direito da Cidade, v. 09, nº 4, p. 2002-2022, 2017.

SCHERER-WARREN, Ilse; LUCHMANN, Lígia. Movimentos sociais e participação. Florianópolis: Editora UFSC, 2011.

SANTA CRUZ DO SUL. Plano municipal de gestão integrada de resíduos sólidos [2013]. Disponível em:

<http://www.santacruz.rs.gov.br/download2017/meioambiente/Plano\%20Municipal\%20de\%2 0Gestao\%20Integrada $\% 20$ de $\% 20$ Residuos $\% 20$ Solidos $\% 20 \mathrm{de} \% 20$ Santa $\% 20 \mathrm{Cruz} \% 20 \mathrm{do} \% 20$ Sul-RS.pdf> Acesso em: 13/03/2018.

SILVEIRA, Rosí C. E.; SCHMITZ, José A. K.; SANTOS, Willian G. Avanços e Retrocessos do Fórum de Ação pela Coleta Seletiva Solidária em Santa Cruz do Sul - FACS. In: Anais do IX Simpósio Internacional de Qualidade Ambiental. Porto Alegre, ABES, 2014, 11p. SONSNISKI, Cristina. Repassando fronteiras entre o lixo e o corpo: estudo etnográfico sobre o cotidiano de recicladores, catadores e carroceiros na Ilha Grande dos Marinheiros. Dissertação de Mestrado em Antropologia, Universidade Federal do Rio Grande do Sul, UFRGS, Porto Alegre, RS. 2006.

TARROW, Sidney. O poder em movimento: movimentos sociais e confronto político. Petrópolis: Vozes, 2009.

WIRTH, Ioli G. Resíduos sólidos: geração de trabalho e renda. Santa Cruz do Sul, 2013. Apresentação feita durante a I Conferência Regional de Meio Ambiente do Vale do Rio Pardo.

WIRTH, Ioli G.; OLIVEIRA, Cristiano B. A PNRS e os modelos de gestão. In: IPEA. Catadores de materiais recicláveis: um encontro nacional. Brasília: IPEA, 2015.

\section{Sobre os autores:}

Cristiano Benites Oliveira possui licenciatura plena em Ciências Sociais pela Universidade Federal do Rio Grande do Sul, mestrado em Ciências Sociais pela Pontifícia Universidade Católica do Rio Grande do Sul e doutorado em Ciências Sociais pela Universidade do Vale do Rio dos Sinos. Atualmente é professor na Universidade de Santa Cruz do Sul. Endereço Eletrônico: cbenites@unisc.br

César Hamilton Brito Góes possui graduação em Ciências Sociais na Universidade Federal do Rio Grande do Sul, mestrado e doutorado em Sociologia, ambos pela UFRGS. Realizou estágio de doutoramento-sanduíche na Universidade de Granada, entre 2004-2005. Atualmente é professor adjunto da Universidade de Santa Cruz do Sul, onde atua desde 1994. E-mail: cgoes@unisc.br 